\title{
Supplement Figures
}

Figure 1S: Soil respiration rate (in $\mu \mathrm{mol} \mathrm{CO}_{2} \mathrm{~m}^{-2} \mathrm{~s}^{-1}$ ) for control (a), PyOM (b) and wood (c). Error bars represent the standard error of the mean $(n=3)$

Figure 2S: Cumulative losses of PyOM-C (a) and wood-C (b) as $\mathrm{CO}_{2}$ in \% of the initial $\mathrm{C}$ input derived from equation 4. The black line represents losses under ambient $\mathrm{N}$ deposition and the grey line losses under increased $\mathrm{N}$. Continuous line represent the mean and the dashed line the standard error of the mean $(n=3)$.

Figure 3S: Cumulated losses as DOC for PyOM (a) and Wood (b) expressed as \% of initially added organic input-C. Empty symbols represent the ambient $\mathrm{N}$ treatment and full symbols represent the increased $\mathrm{N}$ treatment. Error bars represent the standard error of the mean $(n=3)$. 


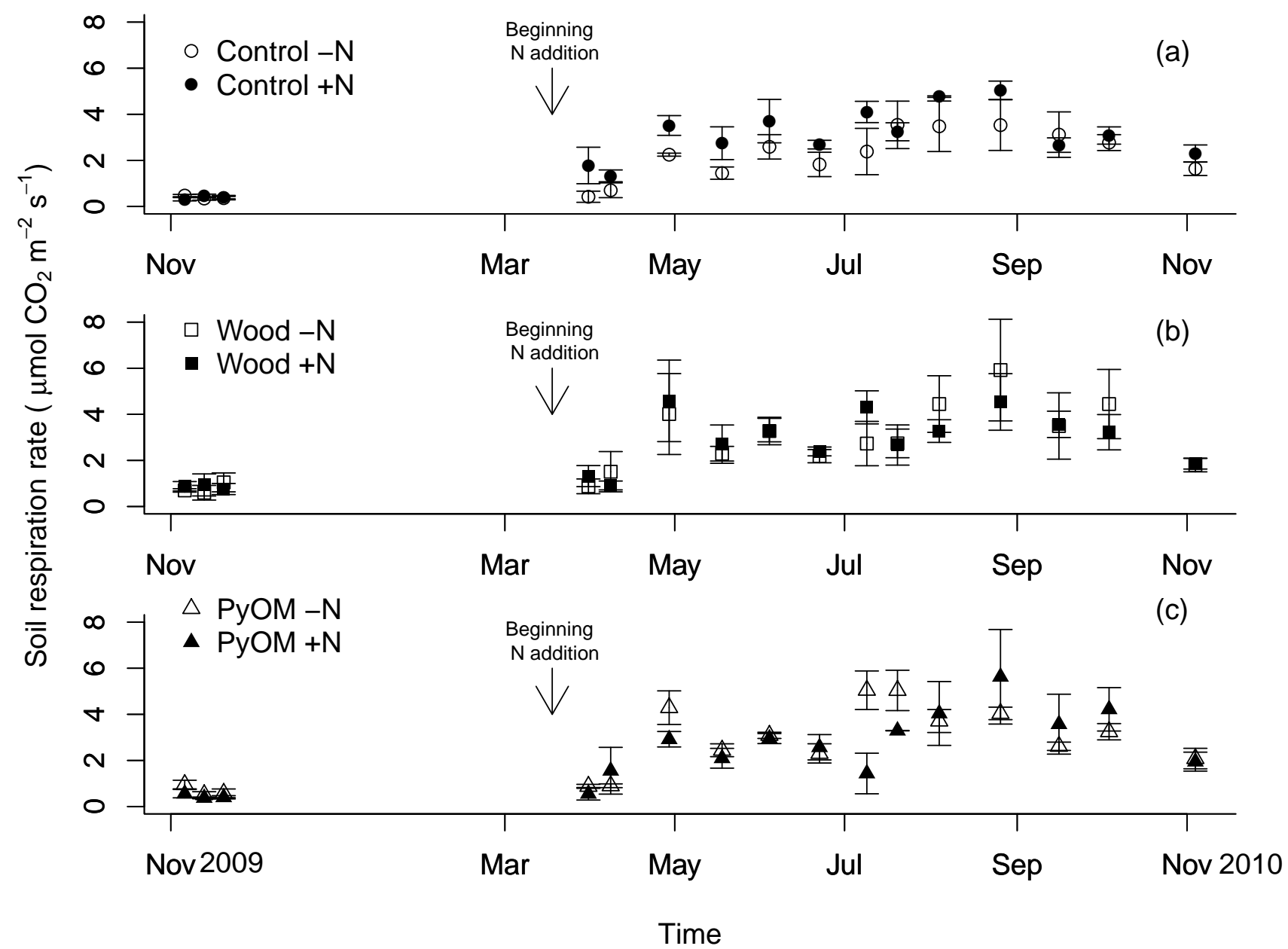

Figure 1S 

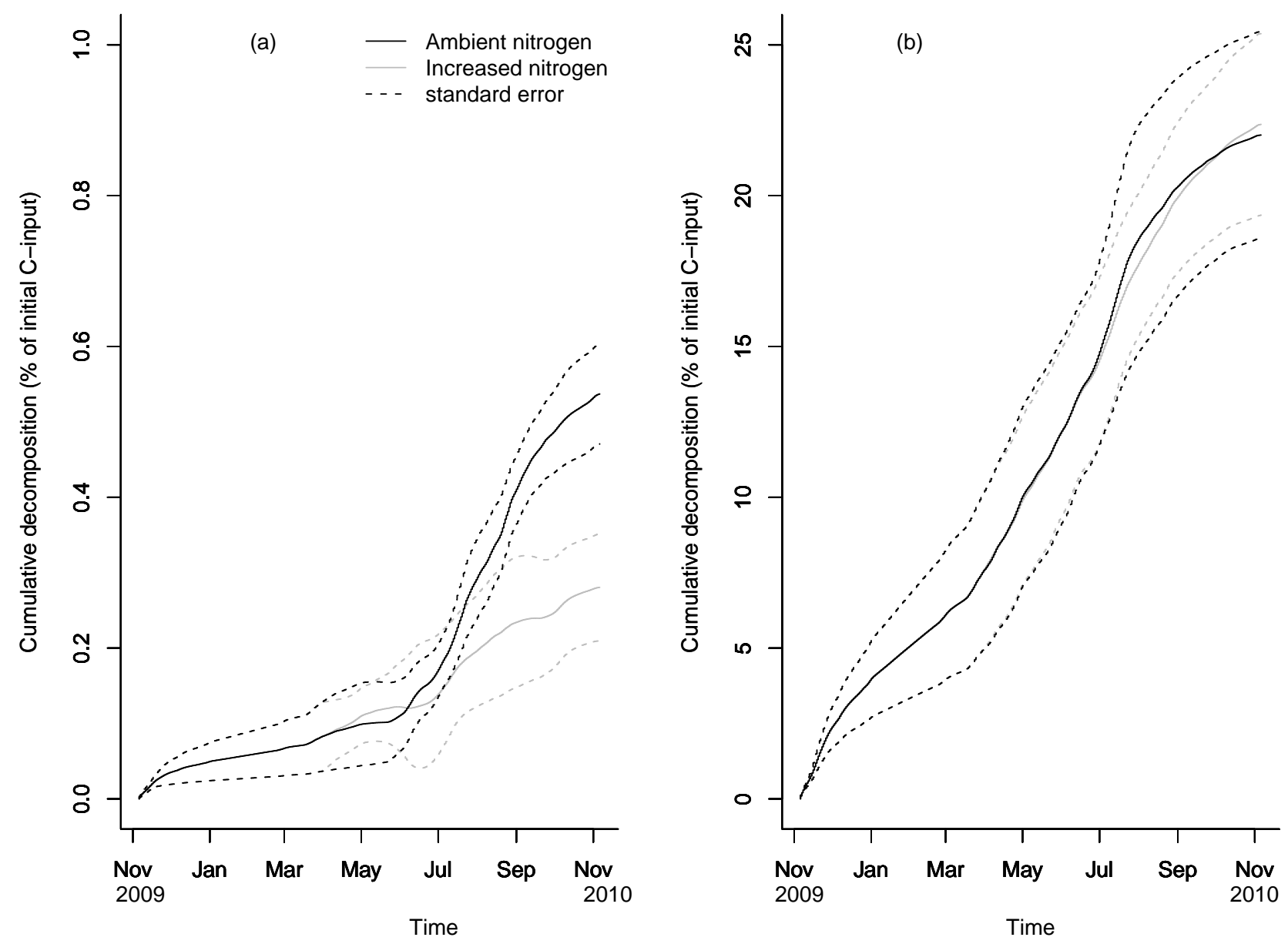

Figure 2S 

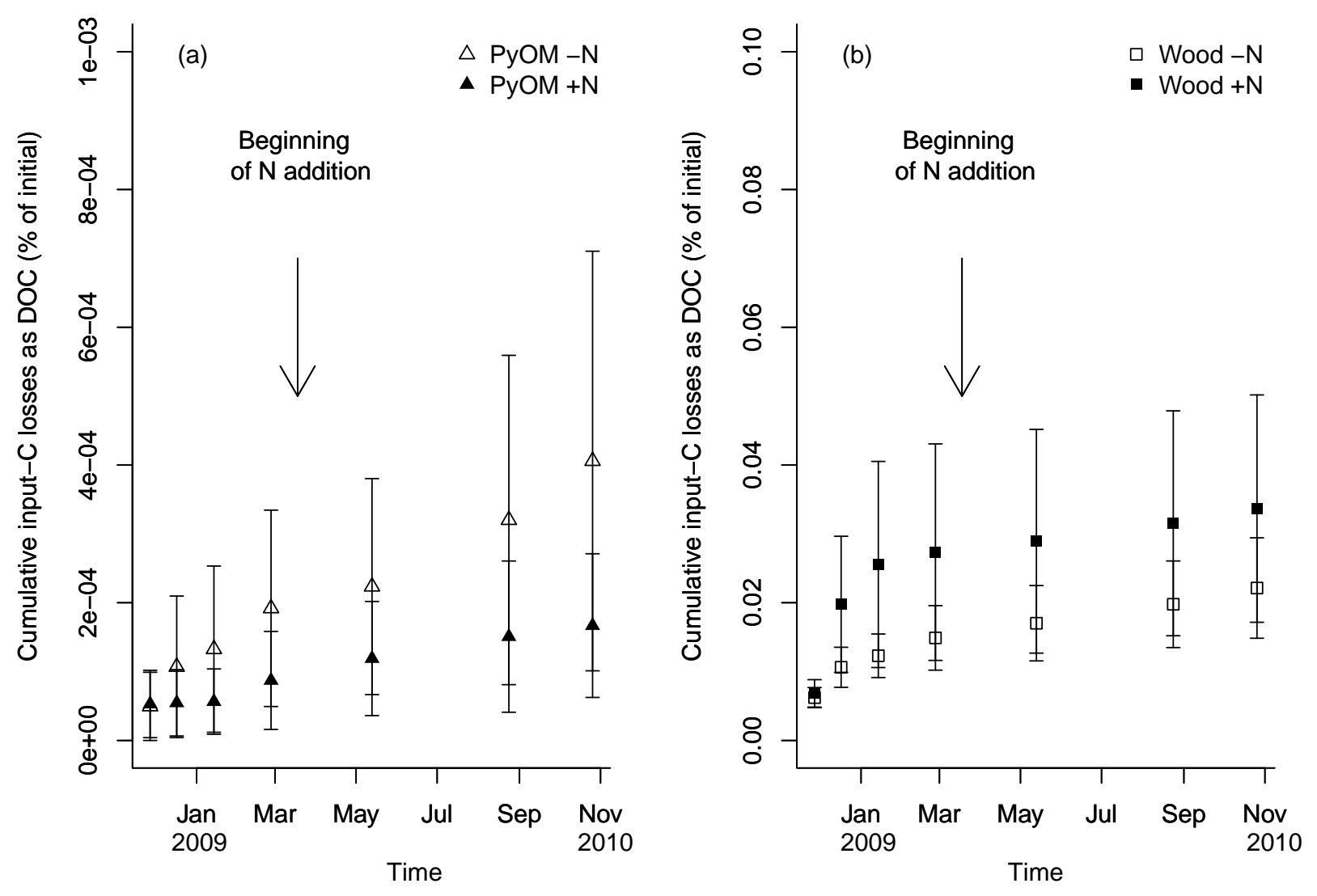

Figure 3S 